\title{
Synergistic effect of Ceftriaxone and diclofenac against Escherichia Coli
}

\author{
Amir Zaman Khan ${ }^{1}$, Shah Zaman ${ }^{1}$, Sardar Muhammad², Riaz Nasim¹, Mohsina Haq ${ }^{2}$, Muhammad Luqman ${ }^{1}$
}

\section{ABSTRACT}

Background: The emergence of resistant strains of bacteria has rendered many useful antibiotics ineffective. The researchers are forced to try combination of two or more antibiotics, or addition of a non- antibacterial to them. Ceftriaxone, a third-generation cephalosporin agent is used to treat many infectious diseases, especially those caused by members of Enterobacteriaceae family. We tested the efficacy of ceftriaxone, alone and in combination with various concentrations of diclofenac sodium, against Escherichia coli.

Objective: To study the synergistic effect of ceftriaxone and its combination with non-antibiotic drug diclofenac sodium against Escherichia coli ATCC 25922 isolate.

Material and Methods: Agar well diffusion technique was applied. $30 \mu \mathrm{l}$ of solutions of ceftriaxone, and its combination with different concentrations of diclofenac sodium and DMSO were transferred aseptically into the wells. Agar plates were placed in incubator at $37^{\circ} \mathrm{C}$ for 24 hours. Mean zone of inhibition of each drug was calculated.

Results: Ceftriaxone $30 \mu \mathrm{g}$ formed a zone of inhibition of $35 \mathrm{~mm}$. Its combination with $25 \mu \mathrm{g}$ and $50 \mu \mathrm{g}$ of diclofenac sodium formed zone of inhibition of $37.5 \mathrm{~mm}$ while its combination with $100 \mu \mathrm{g}$ diclofenac sodium formed a zone of inhibition of $38.6 \mathrm{~mm}$ and formed $39.8 \mathrm{~mm}$ zone of inhibition when combined with $200 \mu \mathrm{g}$ diclofenac sodium.

Conclusion: Ceftriaxone activity increased when combined with different concentrations of diclofenac sodium drug showing a synergistic effect of their combination.

Key words: ceftriaxone, Diclofenac sodium, E. coli, Synergism

This article may be cited as: Khan AZ, Zaman S, Muhammad S, Nasim R, Haq M, Luqman M.

Synergistic effect of Ceftriaxone and diclofenac against Escherichia Coli. J Saidu Med Coll Swat 2021;11(1):50-55

\section{INTRODUCTION}

Antibiotics have significantly enhanced the quality of life and increased life expectancy i by combating infectious diseases. The emergence of resistant strains of various microbes has rendered the antibiotics ineffective ${ }^{1}$. Ceftriaxone, a thirdgeneration cephalosporin is a broad-spectrum antibacterial drug which inhibits cell wall synthesis. It has a broad spectrum of activity against many microbes, but especially effective against $E$. Coli and other members of Enterobacteriaceae family) ${ }^{2}$. However, there are increasing reports of developing resistance against this valuable drug. World Health Organization (WHO) has recognized ceftriaxoneresistant to members of Enterobacteriaceae family as pathogens of clinical importance. Resistant microbes can lead to an increase in mortality and can cause delay in treating infectious diseases even leading to death. Reports suggest increase in the resistant strains of E.coli against third generation cephalosporins since $2004^{3}$.

There are many ways where the bacteria can be intrinsically resistant to cepahlosporins. One of the

1.Department of Pharmacology, Peshawar Medical College

2.Department of Microbiology, Peshawar Medical College.

Correspondence: Dr. Amir Zaman Khan

Department of Pharmacology Peshawar, Pakistan

Peshawar Medical College

Cell: 03329303201 EMail: amirzaman36@gmail.com mechanism is that the pathogens can express certain enzymes like cephalosporinase which can deactivate and destroy the antibiotic. They can also modify the antibiotic target, Penicillin binding protein, due to which the $\beta$-lactams bind poorly and it becomes ineffective. Bacteria can express efflux pumps which exports the drug out of the cell. The microbe can prevent the drug from reaching its target by decreasing the entry or uptake of the antimicrobial agent ${ }^{4}$.

It has also been observed in a study that there is an emerging resistance against carbapenems and colistin, which is very alarming because these drugs are our last hope. Antibiotic resistant of gram-negative bacteria is evolving into a worldwide crisis and WHO has named it as one of the top three global health threats. Therefore, urgent measures need to be taken to address the problem of increasing bacterial resistance against antimicrobials. Therefore, we must look for agents that can prolong and boost the efficacy of antibiotics against such pathogens. Treatment of Gram negative bacteria is already becoming challenging and problematic. Combining antibiotics with non-antibiotics is proving to be an innovative strategy to improve the efficacy of antibiotics fight the pathogens. Antibiotic-non antibiotic approach is successfully applied to treat many infections caused by gram-negative and gram-positive bacteria, malarial infections, tuberculosis and HIV diseases for long time quite some time ${ }^{5}$ 
So action needs to be taken to protect the already existing antibacterial agents and devise strategies to produce novel agents against resistant pathogens ${ }^{6}$.

The synergism between antibiotic and nonantibiotic combination can emerge as a valuable tool to overcome the problem of bacterial resistance to antibiotic by increasing the efficacy of antimicrobial agents ${ }^{7}$.

The irrational and inappropriate use of antibiotics have caused them to become resistant to pathogens ${ }^{8}$. To fight against this nuisance, search for new compounds is the need of the moment which can exert their own antibacterial effect or they can enhance the effect of antibiotic drugs. These compounds are known as 'non-antibiotics' as these agents are used to treat non-infectious pathological conditions but they possess their own anti-bactericidal action ${ }^{9}$.

Diclofenac is a non-steroidal anti-inflammatory drug (NSAID), which has shown antibacterial activity against many gram-negative and grampositive bacteria. Its antibacterial action is reported to be due to its ability to inhibit DNA synthesis in bacteria ${ }^{11}$. Different antibiotic combination therapies have been introduced previously to decrease resistance such as Augmentin, co-trimoxazole and rifampicin and isoniazid. Therefore, antibiotic-non-antibiotic combinations are under trial as they can increase inhibitory effect of antibiotics and decreasing antibiotic resistance.

According to one study, gentamycin plus diclofenac combination had more effect than giving gentamycin alone ${ }^{9}$. In our study we searched for the combined effect of ceftriaxone with diclofenac sodium on Escherichia coli ATCC 25922.

\section{MATERIALS AND METHODS}

This experimental study was conducted in laboratory of Agriculture University of Peshawar, from January 2019- June 2019. American type culture collection (ATCC) isolate of Escherichia coli ATCC 25922 was taken. Ceftriaxone and diclofenac sodium were obtained in powdered form from Astella Pharma. The powdered drugs were dissolved in solution of dimethyle sulfoxide
(DMSO). Bacteria was grown on MacConkeyagar and kept in incubator for 24 hours. Bacteria grown were transferred into falcon tubes containing Mueller Hinton broth with sterilized loop. These tubes were then incubated at 37C. Mueller Hinton agar Media was used for antibiotic susceptibility test. Media used were made by Oxoid Limited, United Kingdom.

The standard inocula were spread on sterilized Mueller Hinton agar through a sterilized glass spreader to get the bacterial lawn. Wells of $4 \mathrm{~mm}$ in diameter and $5 \mathrm{~mm}$ depth were punched in the agar plates using a sterile borer.

The test solutions were prepared by dissolving the test drugs in $10 \mathrm{ml}$ of DMSO. Powdered form of ceftriaxone alone and its combination with Diclofenac sodium were weighed and dissolved in $10 \mathrm{ml}$ of DMSO in separate beakers with separate stirrers to avoid any mixing of the solutions. $30 \mu \mathrm{l}$ solutions of $30 \mu \mathrm{g}$ of Ceftriaxone were prepared and $30 \mu \mathrm{g}$ Ceftriaxone in combination with $200 \mu \mathrm{g}$, $100 \mu \mathrm{g}, 50 \mu \mathrm{g}$ and $25 \mu \mathrm{g}$ of diclofenac solutions were prepared and $30 \mu$ of each solution were transferred aseptically into the wells. DMSO was used as control. Agar plates were placed in around each well of the drug was measured at two planes and mean of these two were calculated. Similarly, mean zones of inhibition formed around the three wells of each drug were calculated ${ }^{10}$.

Mean surface area of zone of inhibition was calculated by using $\pi r^{2}$ formula, where ' $r$ ' is the radius of zone of inhibition. Percentage change in incubator at $37^{\circ} \mathrm{C}$ for 24 hours. Zone of inhibition surface area with the combination against ceftriaxone alone was calculated by the formula (BA)/A×100.

$(A=$ surface area of zone of inhibition due to ceftriaxone only and $B=$ surface area of zone of inhibition due to the combined effect of ceftriaxone and diclofenac combination)

This experiment was performed inside a biosafety cabinet to avoid any contamination of the isolates. Statistical analysis was performed on SPSS version 21 applying student t-test on the mean of two variables. $p$-value less than 0.05 was taken as significant. 


\section{RESULTS}

The mean zones of inhibition with increasing doses of diclofenac in combination have expanded as compared to the ceftriaxone alone zone of inhibition. This shows that Escherichia coli have high sensitivity to the action of diclofenac sodium and ceftriaxone combination as compared to ceftriaxone alone.

Ceftriaxone $30 \mu \mathrm{g}$ formed a mean zone of inhibition of $35 \mathrm{~mm} \pm 2.29$. When combined with $25 \mu \mathrm{g}$ and $50 \mu \mathrm{g}$ of diclofenac solution showed increased zone of inhibition of $37.5 \mathrm{~mm}$ which was statistically insignificant by applying student t-test (p-value >0.05). On the basis of surface area, ceftriaxone area of inhibition increased to $14.4 \%$ when combined with $25 \mu \mathrm{g}$ and $14.5 \%$ when combined with $50 \mu \mathrm{g}$ diclofenac sodium.

Ceftriaxone $30 \mu \mathrm{g}$ when combined with $100 \mu \mathrm{g}$ diclofenac showed a zone of inhibition of $38.6 \mathrm{~mm}$, which is significant as p-value is 0.05 , showed an increase of $22 \%$ surface area of inhibition of ceftriaxone
Ceftriaxone activity increased from $35 \mathrm{~mm}$ to 39.8 $\mathrm{mm}$ when combined with $200 \mu \mathrm{g}$ of diclofenac, which shows significance as the p-value is $<0.05$, an increase of $29 \%$ surface area of inhibition of ceftriaxone was noted.

DMSO, was used a solving agent and a negative control, no zone of inhibition was observed in the plates where DMSO was used alone.

Fig 1. Comparison of Escherichia coli ATCC 25922 sensitivity to ceftriaxone and its combination with different doses of diclofenac sodium.

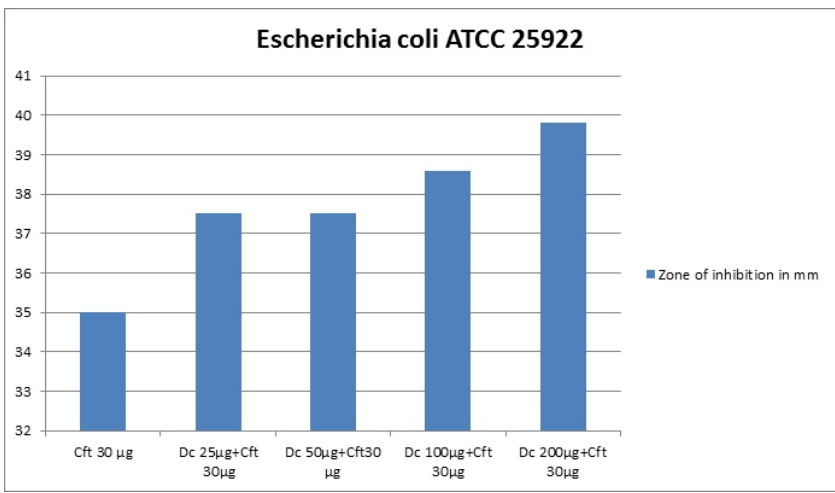

Table 1. Escherichia coli ATCC 25922 sensitivity to ceftriaxone alone and different combinations of diclofenac sodium with ceftriaxone.

\begin{tabular}{|c|c|c|c|}
\hline Drugs & Dose & $\begin{array}{c}\text { Mean zone of } \\
\text { inhibition } \pm \text { SD }(\mathrm{mm})\end{array}$ & $p$-value \\
\hline Ceftriaxone & $30 \mathrm{g \mu}$ & $35 \pm 2.29$ & \\
\hline \multirow{4}{*}{$\begin{array}{l}\text { Diclofenac Sodium + } \\
\text { Ceftriaxone } 30 \mathrm{g \mu}\end{array}$} & $25 g \mu+30 g \mu$ & $37.5 \pm 0.50$ & 0.13 \\
\hline & $50 g \mu+30 g \mu$ & $37.5 \pm 1.50$ & 0.18 \\
\hline & $100 g \mu+30 g \mu$ & $38.6 \pm 0.57$ & 0.05 \\
\hline & $200 g \mu+30 g \mu$ & $39.8+1.75$ & 0.04 \\
\hline DMSO & $99 \%$ & 0 & \\
\hline
\end{tabular}

Table 2. Escherichia coli ATCC 25922 sensitivity to ceftriaxone alone and different combinations of diclofenac sodium and ceftriaxone

\begin{tabular}{|c|c|c|c|}
\hline Drugs & Dose & $\begin{array}{l}\text { Area of inhibition } \\
(\mathrm{mm})\end{array}$ & $\begin{array}{l}\text { \% increase of } \\
\text { ceftriaxone on } \\
\text { the basis of } \\
\text { surface area }\end{array}$ \\
\hline Ceftriaxone & $30 \mathrm{g \mu}$ & 964.37 & \\
\hline \multirow{4}{*}{$\begin{array}{l}\text { Diclofenac Sodium + } \\
\text { Ceftriaxone } 30 \mathrm{g \mu}\end{array}$} & $25 g \mu+30 g \mu$ & 1104.04 & 14.4 \\
\hline & $50 g \mu+30 g \mu$ & 1105.08 & 14.5 \\
\hline & $100 g \mu+30 g \mu$ & 1173.84 & 22 \\
\hline & $200 g \mu+30 g \mu$ & 1247.17 & 29.3 \\
\hline
\end{tabular}




\section{DISCUSSION}

The strategy of combining of antibiotic with nonantibiotic to combat resistance problems in bacteria has been successfully applied in various studies. Synergism between the antibiotics and non-antibiotics can be beneficial as many of the non-antibiotic agents have weak antibacterial effects making them unsuitable to use alone ${ }^{12}$.

These non-antibiotic drugs can enhance the invitro movement of antibiotic against the bacteria. These agents increase the lethal effects and efficacy of antimicrobials when both non-antibiotic and the antibiotics are taken together, and also change the pathogenicity of bacteria by modifying their physiology ${ }^{13}$.

Amlodipine, an anti-hypertensive agent increased the activity of an antibiotic, streptomycin, by increasing the diameter of zone of inhibition of streptomycin against standard bacterial strains on disk diffusion method ${ }^{14}$.

Non steroidal anti-inflammatory drugs can be used to increase the efficacy of certain antibiotics and can serve as non-antibiotics. Aspirin increase the susceptibility of metronidazole, amoxicillin and clarithromycin in inhibiting growth of Helicobacter pylori by Minimum inhibitory concentration (MIC) method ${ }^{15}$.

Diclofenac sodium also reduced the MIC of antibiotics like ciprofloxacin, amoxicillin/clavulinic acid, cefoperazone, gentamycin, tetracycline and imipenam when used against Proteus mirabilis isolated from diabetic foot ulcer patients ${ }^{16}$.

Diclofenac sodium has been reported to increase the antibacterial activity of many antibiotics when they are co-administered. Diclofenac when given in combination with ceftriaxone in patients increased the elimination half-life of the antibiotic when compared with ceftriaxone alone treated group of patients on liquid chromatography ${ }^{17}$.

The combined effect of diclofenac with different antibiotic agents tested on Escherichia coli showed that it reduces the MIC of the antibacterial drugs on the resistant strains of the pathogen ${ }^{18}$.Diclofenac showed synergistic activity when used in combination with ampicillin, amoxicillin, augmentin, cephalexin, cephradine, cefotaxime, ciprofloxacin and gentamicin against Klebsiella pneumoniae ATCC 10031 and Pseudomonas aeruginosa ATCC $10145^{19}$.

Streptomycin $10 \mu \mathrm{g}$ formed a zone of inhibition of $17.4 \mathrm{~mm}$ against Escherichia coli 74. When combined with a $100 \mu \mathrm{g}$ of diclofenac sodium, increase was noted in the zone of inhibition of streptomycin from $17.4 \mathrm{~mm}$ to $18.1 \mathrm{~mm}$ which showed an increase of $8.20 \%$ in area of inhibition of streptomycin ${ }^{20}$.

Streptomycin $10 \mu \mathrm{g}$, increased the zone of inhibition from $18.6 \mathrm{~mm}$ to $19.4 \mathrm{~mm}$ when coadministered with $100 \mu \mathrm{g}$ of diclofenac against Escherichia coli ATCC 25922, an increase 8.74\% surface area of streptomycin on the basis of $\pi r^{221}$.

In our study, increase in the activity of ceftriaxone $30 \mu \mathrm{g}$ was noted on Escherichia coli ATCC 25922 when combined with a non-antibiotic drug, diclofenac sodium. It increased the mean zone of inhibition of ceftriaxone $30 \mu \mathrm{g}$ from $35 \mathrm{~mm}$ to 37.5 $\mathrm{mm}$ in $25 \mu \mathrm{g}$, showing an increase in surface area of ceftriaxone by $14.4 \%$.

It also showed a mean zone of inhibition increase of $37.5 \mathrm{~mm}$ when ceftriaxone combined with 50 $\mu \mathrm{g}$, showing an increase in surface area of ceftriaxone by $14.5 \%$ on the basis of $\pi r^{2}$. The zone of inhibition was increased to $38.6 \mathrm{~mm}$ with 100 $\mu \mathrm{g}$, showing an increase of $22 \%$ surface area of the antibiotic and to $39.8 \mathrm{~mm}$ with $200 \mu \mathrm{g}$ diclofenac, increasing the surface area of ceftriaxone by $29.3 \%$.

DMSO was used as a solvent for the drugs used, which were in powdered form. We also made separate wells for DMSO against Escherichia coli ATCC 25922, as negative control, where no zone of inhibition was formed by the solvent.

\section{CONCLUSIONS}

1) It is concluded that the effect of combination of $30 \mu \mathrm{g}$ ceftriaxone is significantly effective in combining with $100 \mu \mathrm{g}$ and $200 \mu \mathrm{g}$ of diclofenac sodium.

2) Combined effect of antibiotics-non-antibiotics against bacteria can be used as a valuable tool to get additional anti-bacterial effect. 


\section{REFERENCES}

1. Akilandeswari K, Ruckmani K, Abirami S. Enhancement of the efficacy of antibiotics ciprofloxacin and gentamycin against gram positive and gram negative micro organism with non antibiotic Nimesulide. Int $\mathrm{J}$ pharm pharmsci. 2013;5(3):627-30.

2. Arumugham VB, Cascella M. Third Generation Cephalosporins. StatPearls [Internet]: StatPearls Publishing; 2019.

3. Chua KY, Stewardson AJ. Individual and community predictors of urinary ceftriaxone-resistant Escherichia coli isolates, Victoria, Australia. Antimicrobial Resistance \& Infection Control. 2019;8(1):36-42.

4. Munita JM, Arias CA. Mechanisms of antibiotic resistance. Virulence mechanisms of bacterial pathogens. 2016:481-511.

5. Schneider EK, Reyes-Ortega F, Velkov T, Li J. Antibioticnon-antibiotic combinations for combating extremely drug-resistant Gram-negative 'superbugs'. Essays in biochemistry. 2017;61(1):115-25.

6. Opal SM. Non-antibiotic treatments for bacterial diseases in an era of progressive antibiotic resistance. BioMed Central; 2016.

7. Tyers M, Wright GD. Drug combinations: a strategy to extend the life of antibiotics in the 21st century. Nature Reviews Microbiology. 2019;17(3):141-55.

8. Machowska A, Stålsby Lundborg C. Drivers of irrational use of antibiotics in Europe. International journal of environmental research and public health. 2019;16(1):27-35.

9. Akilandeswari K, Ruckmani K. Studies on anti microbial potential of non-antibiotics on resistant bacteria-A Review. Journal of Young Pharmacists. 2015;7(2):63-69.

10. Padma, R., \& Yalavarthy, P. D. (2015). Screening of diclofenac for antibacterial activity against pathogenic microorganisms. Int. J. Adv. Pharm. Biol. Chem, 4(3), 554-558.

11. e Silva AAdL, Silva PM. Non-Antibiotic Compounds: The Activity of the NSAID Diclofenac on Bacteria-A Review. Int J Curr Microbiol App Sci. 2018;7(12):340-51.

12. Sun W, Weingarten RA, Xu M, Southall N, Dai S, Shinn P, et al. Rapid antimicrobial susceptibility test for identification of new therapeutics and drug combinations against multidrug-resistant bacteria. Emerging microbes \& infections. 2016;5(1):1-11.

13. Thakur $M$, Thakur $S$, Jaiswal $H$. Screening of Antimicrobial effect of some Non-antibiotics (anti-hypertensive) Against some selected Microorganisms. International Journal of Pharma Professional's Research. 2017;8(2):1414-8.

14. Kumar KA, Mazumdar K, Dutta NK, Karak P, Dastidar SG, Ray R. Evaluation of synergism between the aminoglycoside antibiotic streptomycin and the cardiovascular agent amlodipine. Biological and Pharmaceutical Bulletin. 2004;27(7):1116-20.

15. Wang W, Wong W, Dailidiene D, Berg D, Gu Q, Lai $\mathrm{K}$, et al. Aspirin inhibits the growth of Helicobacter pylori and enhances its susceptibility to antimicrobial agents. Gut. 2003;52(4):490-5.
16. Hegazy WAH. Diclofenac inhibits virulence of Proteus mirabilis isolated from diabetic foot ulcer. African Journal of Microbiology Research. 2016;10(21):733-43.

17. Merle-Melet M, Bresler L, Lokiec F, Dopff C, Boisse $P$, Dureux J. Effects of diclofenac on ceftriaxone pharmacokinetics in humans. Antimicrobial agents and chemotherapy. 1992;36(10):2331-3

18. Ahmed EF, El-Baky RMA, Ahmed ABF, Fawzy N, Aziz N, Gad G. Evaluation of antibacterial activity of some non-steroidal anti-inflammatory drugs against Escherichia coli causing urinary tract infection. Afr J Microbiol Res. 2016;10(34):1408-16.

19. Ahmed EF, El-Baky RMA, Ahmed ABF, Waly NG Gad GFM. Antibacterial activity of some nonsteroidal anti-inflammatory drugs against bacteria causing urinary tract infection. Am J Infect Dis Microbiol. 2017;5:66-73.

20. Annadurai S, Guha-Thakurta A, Sa B, Ray SDR, Chakrabarty A. Experimental studies on synergism between aminoglycosides and the antimicrobial antiinflammatory agent diclofenac sodium. Journal of chemotherapy. 2002;14(1):47-53.

21. Dutta NK, Annadurai S, Mazumdar K, Dastidar SG Kristiansen JE, Molnar J, et al. Potential management of resistant microbial infections with a novel non-antibiotic: the anti-inflammatory drug diclofenac sodium. International journal of antimicrobial agents. 2007;30(3):242-9.
DATA SHARING STATEMENT: The data that support the findings of this study are available on request from the corresponding author. The data are not publicly available due to privacy or ethical restrictions.

CONFLICT OF INTEREST: Authors declare no conflict of interest.

GRANTED SUPPORT AND FINANCIAL DISCLOSURE:
Nil

\section{AUTHOR'S CONTRIBUTION}

Following authors have made substantial contributions to the manuscript as under

Khan AZ, Zaman S:Concept and design of study, Collection of data, statistical analysis

Muhammad S: Writing of manuscript, critical review of manuscript

Nasim R, Haq M: Analysis and interpretation of data, statistical analysis

Luqman M: Data collection, bibliography

Authors agree to be accountable for all aspects of the work in ensuring that questions related to the accuracy or integrity of any part of the work are appropriately investigated and resolved. 